\title{
DAMPAK PERUBAHAN JUMLAH LAJUR RUAS JALAN RAYA KALIBATA
} JAKARTA SELATAN

\section{Zahara Dwicahyanti, A.R. Indra Tjahjani}

Universitas Pancasila Jakarta, Indonesia

Email: zaharadwicahyanti@gmail.com, arindratjahjani@univpancasila.ac.id

\begin{tabular}{|c|c|}
\hline INFO ARTIKEL & \multirow{24}{*}{$\begin{array}{l}\text { ABSTRAK } \\
\text { DKI Jakarta sebagai Ibukota Indonesia, merupakan tempat } \\
\text { berlangsungnya pusat bisnis, politik dan kebudayaan. } \\
\text { Pembuatan lalu lintas dan angkutan jalan yang terpadu perlu } \\
\text { dilakukan pengembangan jaringan lalu lintas dan angkutan } \\
\text { jalan untuk menghubungkan wilayah. Ruas Jalan Raya } \\
\text { Kalibata berfungsi sebagai penghubung antara wilayah Jakarta } \\
\text { Selatan dengan wilayah Jakarta Timur dalam sistem } \\
\text { transportasi. Selain itu, pada jalan ini terdapat pintu keluar } \\
\text { masuk untuk pusat perbelanjaan dan Apartemen Kalibata City, } \\
\text { kantor kementerian dan pertokoan. Tingkat aktivitas pada Jalan } \\
\text { Raya Kalibata cukup tinggi, serta berperan penting dalam } \\
\text { melayani arus lalu lintas yang cukup tinggi. Analisis terhadap } \\
\text { kinerja lalu lintas dan evaluasi dibutuhkan untuk memperbaiki } \\
\text { atau mempertahankan kinerja dari jalan tersebut. Tujuan } \\
\text { penelitian ini adalah untuk melihat dampak pengurangan lajur } \\
\text { yang memengaruhi kinerja pada ruas Jalan Raya Kalibata. } \\
\text { Metode yang digunakan adalah berdasarkan Manual Kapsitas } \\
\text { Jalan Indonesia (MKJI) } 1997 \text {, dimana nilai derajat kejenuhan } \\
\text { tidak melebihi nilai 0,75. Penelitian dilakukan dengan } \\
\text { meninjau ruas Jalan Raya Kalibata yang dibagi menjadi ke } \\
\text { dalam } 2 \text { segmen. Segmen } 1 \text { adalah ruas jalan yang menuju ke } \\
\text { arah Barat atau Jalan Raya Pasar Minggu. Sedangkan untuk } \\
\text { segmen } 2 \text { menuju ke arah Timur atau Jalan Dewi Sartika. } \\
\text { Pengumpulan data dengan survei dilakukan selama } 2 \text { hari, yaitu } \\
\text { pada hari Selasa, } 6 \text { April } 2021 \text { sampai Rabu, } 7 \text { April } 2021 \text { pada } \\
\text { jam 07.00 - 09.00 WIB. Hasil analisis menunjukan pada } \\
\text { segmen } 1 \text { didapat nilai derajat kejenuhan sebesar 0,766 dan } \\
\text { untuk segmen } 2 \text { nilai derajat kejenuhan sebesar 0,647. }\end{array}$} \\
\hline Diterima & \\
\hline stus 2021 & \\
\hline & \\
\hline & \\
\hline Disetujui & \\
\hline er 2021 & \\
\hline Kata Kunci: kinerja & \\
\hline lalu lintas; ruas & \\
\hline jalan; & \\
\hline & \\
\hline & \\
\hline & \\
\hline & \\
\hline & \\
\hline & \\
\hline & \\
\hline & \\
\hline & \\
\hline & \\
\hline & \\
\hline & \\
\hline & \\
\hline & \\
\hline
\end{tabular}

\section{ABSTRACT}

DKI Jakarta as the capital city of Indonesia, is a center for business, politics and culture. It is necessary to develop an integrated traffic and road transport network to connect regions. The Jalan Raya Kalibata section serves as a link between the South Jakarta area and the East Jakarta area in

$\begin{array}{ll}\text { How to cite: } & \text { Dwicahyanti, Z., \& Tjahjani, A.R. I. (2021) Dampak Perubahan Jumlah Lajur Ruas Jalan Raya } \\ & \text { Kalibata Jakarta Selatan. Jurnal Syntax Admiration 2(9). https://doi.org/10.46799/jsa.v2i9.306 } \\ \text { E-ISSN: } & 2722-5356 \\ \text { Published by: } & \text { Ridwan Institute }\end{array}$


the transportation system. In addition, on this road there are entrances and exits for shopping centers and Kalibata City Apartments, ministry offices and shops. The level of activity on Jalan Raya Kalibata is quite high, and plays an important role in serving the fairly high traffic flow. Analysis of traffic performance and evaluation is needed to improve or maintain the performance of the road. The purpose of this study was to see the impact of lane reduction that affects performance on the Kalibata Highway section. The method used is based on the 1997 Indonesian Road Capacity Manual (MKJI), where the value of the degree of saturation does not exceed the value of 0.75 . The research was conducted by reviewing the Kalibata Highway segment which is divided into 2 segments. Segment 1 is the road that leads to the West or Jalan Raya Pasar Minggu. As for segment 2, head east or Jalan Dewi Sartika. Data Keywords: $\quad$ traffic collection by survey was carried out for 2 days, namely on performance; roads; Tuesday, April 62021 to Wednesday, April 72021 at 07.00 road service level; 09.00 WIB. The results of the analysis show that in segment 1 MKJI 1997; $\quad$ the value of the degree of saturation is 0.766 and for segment 2 Kalibata Highway the value of the degree of saturation is 0.647 .

\section{Pendahuluan}

Jalan berfungsi sebagai suatu prasarana transportasi yang menghubungkan suatu wilayah dengan wilayah lainnya diperuntukan bagi lalu lintas. Terdapatnya jalan dan transportasi pada suatu wilayah dapat membantu pertumbuhan ekonomi dan perkembangan pembangunan suatu daerah.

Bedasarkan UU No. 22 Tahun 2009 Tentang Lalu Lintas dan Angkutan Jalan, untuk membuat lalu lintas dan angkutan jalan yang terpadu perlu dilakukan pengembangan jaringan lalu lintas serta angkutan jalan yang bertujuan untuk menghubungkan wilayah (Negara, 2009).

Pemerintah Provinsi DKI Jakarta meluncurkan program yang disebut Pola Transportasi Makro (PTM) sejak tahun 2003 yang diterapkan untuk mengatasi kemacetan. Berdasarkan Peraturan Gubernur Provinsi DKI Jakarta No 103 Tahun 2007 maksud dari disusunnya PTM adalah untuk menigkatkan pelayanan serta penyediaan jasa transportasi, yang bertujuan untuk menetapkan Rencana Induk Sistem Jaringan Transportasi sebagai perwujudan Tatanan Transportasi Wilayah. Jenis angkutan umum yang dikembangkan seperti busway, KRL, MRT dan LRT (Jakarta, 2007). Hal inilah yang diperlukan Jakarta untuk menjadi pusat bisnis dan membuat pesatnya pertumbuhan ekonomi pada kota ini.

Selain meningkatkan pertumbuhan ekonomi, akses yang mudah untuk keluar masuk ke dalam suatu kota akan membuat masyarakat yang berasal dari luar kota turut bekerja mencari nafkah ke Jakarta, seperti dari Bekasi, Depok, Bogor dan Tangerang dan menyebabkan pergerakkan transportasi di Jakarta cukup cepat. Jalan yang terbatas namun volume kendaraan terus bertambah, menjadi salah satu penyebab terjadinya 
kemacetan pada ibukota ini. Penerapan konsep PTM, diharapkan dapat mengurangi masalah transportasi di Jakarta.

Metode analisis yang digunakan untuk menentukan kinerja lalu lintas adalah menggunakan Manual Kapasitas Jalan Indonesia 1997 MKJI 1997. Manual tersebut telah digunakan oleh berbagai peneliti untuk menentukan kinerja jalan perkotaan di Indonseia. Perbedaan antara penelitian ini dengan penelitian lainnya adalah pada lokasi penelitian, dimana penelitian ini dilakukan pada ruas Jalan Raya Kalibata.

Ruas Jalan Raya Kalibata berfungsi sebagai penghubung antara wilayah Jakarta Selatan dengan wilayah Jakarta Timur. Selain itu, pada jalan ini terdapat pintu keluar masuk untuk pusat perbelanjaan dan Apartemen Kalibata City, kantor kementerian dan pertokoan. Hal ini menyebabkan tingkat aktivitas pada Jalan Raya Kalibata cukup tinggi serta berperan penting dalam melayani arus lalu lintas yang cukup besar. Semakin besarnya arus lalu lintas dan semakin pesatnya aktivitas pada suatu jalan, menyebabkan penurunan kinerja jalan ketika peak hour dan berakibat munculnya kemacetan.

Maksud dari penelitian ini adalah untuk melihat dampak perubahan lajur di Jalan Raya Kalibata. Adapun penelitian ini memiliki tujuan untuk :

1. Menganailis kinerja ruas Jalan Raya Kalibata

2. Mengevaluasi hasil kinerja ruas Jalan Raya Kalibata

Sedangkan batasan masalah untuk penelitian adalah sebagai berikut :

1. Batasan jalan untuk penelitian Jalan Raya Kalibata adalah dari Kementerian Desa, Pembangunan Desa Tertinggal dan Transmigrasi sampai dengan Taman Makam Pahlawan

2. Tidak membahas simpangan dan sistem persinyalan yang ada

3. Metode yang digunakan berdasarkan MKJI 1997

4. Waktu pengamatan dilakukan pada saat peak hour atau volume puncak

5. Pengamatan atau observasi dibatasi pada keadaan cuaca normal

\section{Metode Penelitian}

Ruas Jalan Raya Kalibata termasuk kedalam jalan perkotaan, karena pada jalan ini memiliki ciri - ciri dimana bahwa gerakan kendaraan dipengaruhi oleh 3 sebab, yaitu sebagai berikut (Risdiyanto, 2014):

- Kondisi lingkungan

- Interaksi antara kendaraan

- Efek dari lampu lalu lintas

Lokasi pengumpulan data dilakukan sepanjang garis kuning seperti pada di bawah, yaitu Jalan Raya Kalibata dengan batas dari Kementerian Desa, Pembangunan Desa Tertinggal dan Transmigrasi sampai Taman Makam Pahlawan (TMP). Analisis data dilakukan dalam 2 segmen jalan, yaitu:

- Segmen 1, menuju arah Barat atau Jalan Raya Pasar Minggu 
- Segmen 2, menuju arah Timur atau Jalan Dewi Sartika

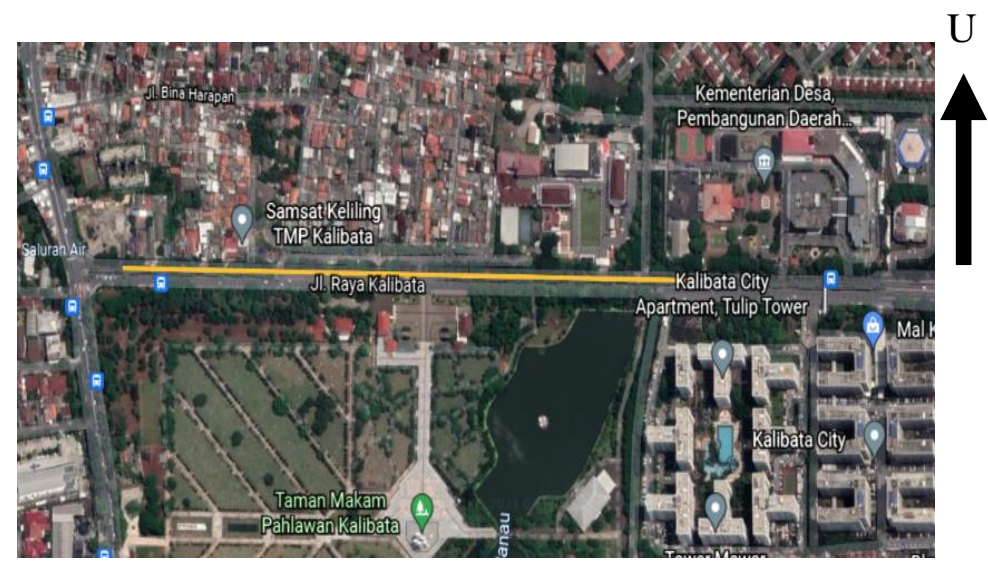

Gambar 1

Lokasi Pengumpulan Data

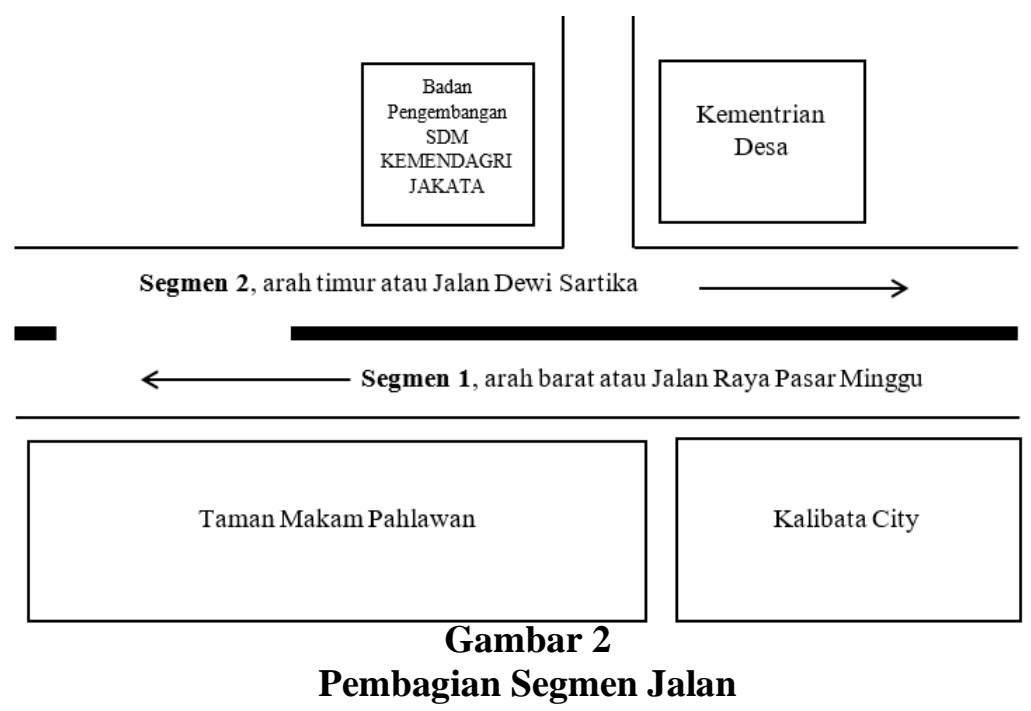

Komponen utama dalam transportasi jalan raya adalah pengemudi, kendaraan, pejalan kaki, dan jalan (Leksmono, 2019). Pembagian batas jalan harus didasarkan pada empat komponen tersebut. Maka ditentukan batas jalan adalah dari Kementerian Desa, Pembangunan Desa Tertinggal dan Transmigrasi sampai Taman Makam Pahlawan ini, dikiranya dapat mewakilkan arus lalu lintas maupun hambatan samping yang ada sepanjang Jalan Raya Kalibata. Hal tersebut dikarenakan dalam pembagian batas jalan ini terdapat Kalibata City, U-Turn, Toko dan parkiran yang menyebabkan arus lalu lintas cukup tinggi.

Penelitian ini dimulai dengan memilih objek yang akan diteliti, selanjutnya mengidentifikasi permasalahan, tujuan penelitian dan batasan masalah. Mengumpulkan tinjauan pustaka yang akan menunjang penelitian dan data-data terkait permasalahan yang dipilih. Setelah data terkumpul, dilakukan analisis dan evaluasi terhadap kinerja jalan. 
Metodologi pengumpulan data yang digunakan adalah sebagai berikut :

\section{Studi Literatur}

Studi literatur merupakan pengumpulan data - data dari literatur atau sumber tertulis yang berhubungan dengan permasalahan yang akan dianalisis, yaitu kinerja lalu lintas di ruas jalan.

2. Survei atau Tinjauan di Lapangan

Survei ini dilakukan untuk mendapatkan data - data yang ada di lapangan, seperti data volume lalu lintas, hambatan samping, kecepatan kendaraan dan data yang dibutuhkan lainnya.

3. Pengambilan Dokumentasi

Pengambilan dokumentasi diperlukan untuk mendukung atau menunjang kelengkapan data permasalahan yang akan dianalisis.

4. Wawancara

Wawancara dilakukan dengan menanyakan langsung pertanyaan kepada narasumber yang dianggap benar yang kemudian akan digunakan sebagai referensi.

Jenis data berdasarkan sumbernya yaitu data primer dan data sekunder. Baik data primer maupun data sekunder merupakan sumber data informasi yang akan dikumpulkan untuk dilakukan analisis lebih lanjut.

Data primer yang perlu dikumpulkan adalah volume lalu lintas, hambatan samping, waktu tempuh kendaraan dan geometrik jalan. Sedangkan untuk data sekunder adalah peta lokasi dan data penduduk.

Pengumpulan data primer yang dibutuhkan, dilakukan selama 2 hari, yaitu pada hari Selasa, 6 April 2021 dan hari Rabu, 7 April 2021. Sebelum menentukan waktu survey, terlebih dahulu dilakukan wawancara kepada 12 responden. Responden yang dipilih, terdiri dari tukang parkir, satpam, pedagang, penghuni Apartemen Kalibata City, dan orang yang sering melewati Jalan Raya Kalibata. Pemilihan responden sendiri berdasarkan pemahaman mengenai Jalan Raya Kalibata. Wawancara ini dilakukan untuk memperkirakan waktu puncak atau peak hour pada ruas jalan ini.

Berdasarkan pendapat para responden, volume lalu lintas tertinggi yang terjadi pada Jalan Raya Kalibata ini adalah selalu pada pagi hari. Maka, dapat diambil kesimpulan dari hasil wawancara terhadap 12 responden tersebut, ditetapkan untuk jam pengambilan data arus lalu lintas dilapangan, dilakukan pada jam 07.00 - 10.00 WIB. Pencatatan arus lalu lintas dilakukan setiap periode 15 menit.

Sebelum melakukan survey atau pengamatan secara langsung, hendaknya membuat rancangan survey terlebih dahulu. Hal ini bertujuan untuk mengarahkan serta memudahkan apa saja yang harus dilakukan dalam melakukan survey. Diagram alir rancangan survey dapat dilihat pada Gambar 3.7 di bawah. 


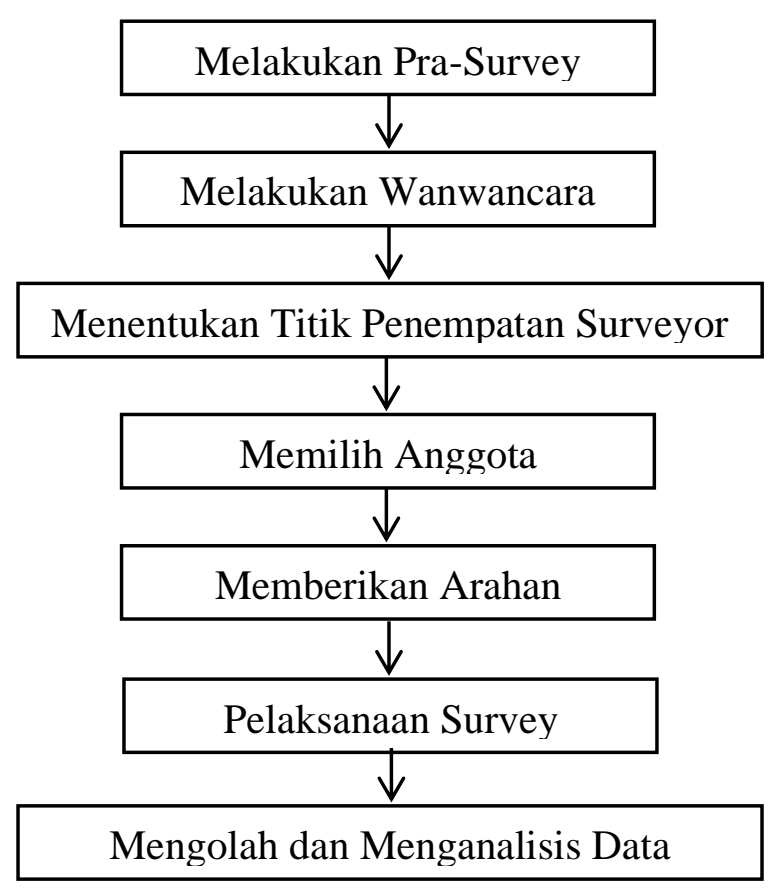

\section{Gambar 3 \\ Rancangan Survei}

Berikut merupakan penjelasan diagram alir rancangan survey :

1. Melakukan pra-survey terhadap kondisi arus lalu lintas pada Jalan Raya Kalibata. Pra-suevey dilakukan selama 5 hari, yaitu ketika weekdays. Bertujuan untuk melihat dan menentukan hari yang tepat untuk dilakukannya survey.

2. Melakukan wawancara kepada tukang parkir, satpam, pedagang, penghuni Apartemen Kalibata City, dan orang yang sering melewati jalan ini. Untuk menentukan waktu pada saat volume tertinggi yang terjadi di Jalan Raya Kalibata.

3. Menentukan titik penempatan surveyor. Titik penempatan surveyor dipilih sebagai tempat yang efisien di sepanjang Jalan Raya Kalibata dengan batas jalan yang telah ditentukan.

4. Menentukan jumlah kebutuhan serta memilih anggota surveyor.

5. Memberikan briefing atau arahan kepada para anggota mengenai apa yang harus dilakukan ketika survey beserta tugasnya masing - masing.

6. Melakukan survey pada titik yang telah ditentukan dan mengikuti rencana yang telah dibuat.

7. Melakukan pengolahan dan analisis data dari hasil survey.

Lokasi penempatan surveyor dapat dilihat seperti pada gambar 3 di bawah. Pada 1 titik survei terdapat 3 orang surveyor dan camera untuk merekam arus lalu lintas untuk kendaraan ringan (Light Vehicle/LV) dan kendaraan berat (Heavy Vehicle/HV). Pembagian tugas dilakukan dengan cara 1 orang surveyor bertugas untuk menghitung arus sepeda motor, satu lainnya menghitung waktu tempuh kendaraan dan satu lagi 
menghitung hambatan samping. Jumlah arus kendaraan ringan dan berat dapat melihat rekaman. Surveyor melakukan pengamatan selama 15 menit.

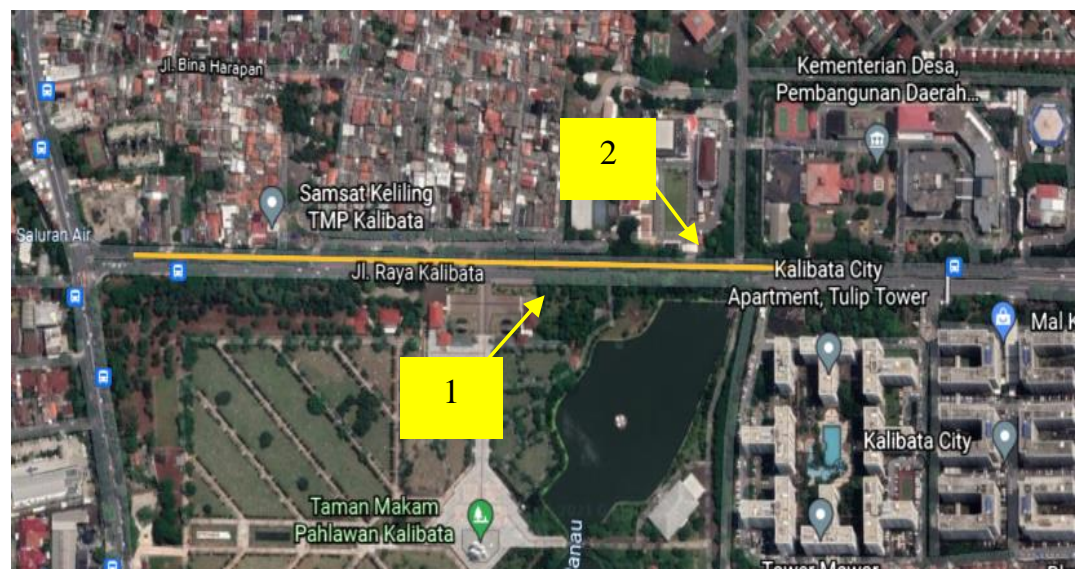

Gambar 4

Penempatan Surveyor

Kinerja ruas jalan merupakan suatu pengukuran yang bersifat kuantitatif dalam menggambarkan kondisi tertentu pada suatu ruas jalan. Kinerja lalu lintas pada ruas jalan dapat ditentukan ketika perhitungan pada volume lalu lintas, kecepatan arus bebas, serta analisis kapasitas telah dihitung (Desembardi et al., 2018).

Metode analisis kinerja ruas jalan dilakukan berdasarkan MKJI 1997 (Indonesia, 1997). Kinerja jalan yang baik nilai dari derajat kejenuhan/Degree of Saturation (DS) tidak melebihi dari angka 0,75. Kemudian dapat ditentukan untuk tingkat pelayanan jalan/Level of Service (LOS) nya.

Berdasarkan MKJI 1997 terdapat variabel-variabel yang perlu ditetapkan dalam menganalisis kinerja lalu lintas. Variabel tersebut adalah arus dan komposisi lalu lintas, kecepatan arus bebas, kapasitas, derajat kejenuhan, kecepatan dan perilaku lalu lintas.

Volume lalu lintas merupakan jumlah dari kendaraan yang melewati suatu ruas jalan tertentu per satuan waktu. Pada teknik lalu lintas, volume merupakan variabel yang penting karena pada dasarnya merupakan proses perhitungan yang berhubungan dengan jumlah gerakan pada periode waktu tertentu dan pada suatu lokasi tertentu (Septiansyah \& Wulansari, 2018). Volume lalu lintas yang digunakan dalam analisis untuk menentukan kinerja lalu lintas pada ruas jalan adalah ketika jalan sedang mengalami masa peak hour. Hal tersebut dikarenakan volume lalu lintas pada masa peak hour lebih tinggi dibandingkan dengan jam lainnya. Data volume lalu lintas yang dihitung dicatat dengan interval waktu selama 15 menit di lapangan, yang kemudian dijumlahkan kedalam interval waktu 1 jam untuk keperluan perhitungan berdasarkan jenis kendaraannya.

Hambatan samping dapat menjadi salah satu penyebab kemacetan di ruas jalan terutama pada kota besar atau jalan perkotaan. Perubahan fungsi ruang yang menyebabkan rumah menjadi kantor atau rumah makan, yang tidak memiliki lahan parkir, menjadikan trotoar atau lajur di jalan dijadikan tempat parkir (Gridoto.com, 2018). 
Kecepatan arus bebas (FV) adalah kecepatan pada tingkat arus nol, yaitu merupakan kecepatan yang akan dipilih oleh pengendara kendaraan bermotor tanpa dipengaruhi oleh kendaraan motor lainya pada jalan (Perhubungan et al., 2015). Berdasarkan MKJI untuk menentukan kecepatan arus bebas dapat dihitung menggunakan persamaan sebagai berikut :

$\mathrm{FV}=\left(\mathrm{FV}_{0}+\mathrm{FV}_{\mathrm{W}}\right) \times \mathrm{FFV}_{\mathrm{SF}} \times \mathrm{FFV}_{\mathrm{CS}}$

Dimana :

$\mathrm{FV}=$ Kecepatan arus bebas kendaraan ringan $(\mathrm{km} / \mathrm{jam})$

$\mathrm{FV}_{\mathrm{O}}=$ Kecepatan arus bebas dasar kendaraan ringan $(\mathrm{km} / \mathrm{jam})$

$\mathrm{FV}_{\mathrm{W}}=$ Penyesuaian lebar jalur lalu lintas efektif $(\mathrm{km} / \mathrm{jam})$

$\mathrm{FFV}_{\mathrm{SF}}=$ Faktor penyesuaian kondisi hambatan samping

$\mathrm{FFV}_{\mathrm{CS}}=$ Faktor penyesuaian untuk ukuran kota

Kapasitas jalan (C) merupakan arus maksimum yang melalui suatu titik jalan yang dinyatakan dalam satuan jam pada kondisi tertentu. Berdasarkan MKJI untuk menentukan kapasitas jalan dapat dihitung menggunakan persamaan sebagai berikut :

$\mathrm{C}=\mathrm{C}_{0} \times \mathrm{FC}_{\mathrm{W}} \times \mathrm{FC}_{\mathrm{SP}} \times \mathrm{FC}_{\mathrm{SF}} \times \mathrm{FC}_{\mathrm{CS}}$

Dimana :

$\mathrm{C}=$ Kapasitas ( $\mathrm{smp} / \mathrm{jam})$

$\mathrm{C}_{\mathrm{O}}=$ Kapasitas dasar (smp/jam)

$\mathrm{FC}_{\mathrm{W}}=$ Faktor penyesuaian lebar jalur lalu lintas

$\mathrm{FC}_{\mathrm{SP}}=$ Faktor penyesuaian pemisahan arah

$\mathrm{FC}_{\mathrm{SF}}=$ Faktor penyesuaian hambatan samping

$\mathrm{FC}_{\mathrm{CS}}=$ Faktor penyesuaian untuk ukuran kota

Derajat kejenuhan atau Degree of Saturation (DS) merupakan rasio arus terhadap kapasitas yang digunakan untuk faktor utama dalam menentukan tingkat kinerja jalan. Rumus untuk mencari DS adalah sebagai berikut :

$D S=\frac{Q}{C}$

Dimana :

$\mathrm{Q}=$ Arus Lalu Lintas (smp/jam)

$\mathrm{C}=$ Kapasitas jalan (smp/jam)

Kecepatan (V) merupakan jarak yang ditempuh kendaraan dalam satuan waktu. Kecepatan merupakan salah satu parameter yang penting dalam lalu lintas, karena dapat memberikan informasi tentang keadaan perjalanan, tingkat pelayanan, serta klasifikasi arus lalu lintas (ilmusipil.com, 2009). Kecepatan dirumuskan sebagai berikut :

$V=\frac{L}{T T}$

Dimana :

$\mathrm{L}=$ Panjang segmen $(\mathrm{km})$

$\mathrm{TT}=$ Waktu tempuh rata-rata $(\mathrm{jam})$

Tingkat pelayanan jalan atau juga bisa disebut Level of Service (LOS) adalah suatu gambaran dari kondisi arus lalu lintas dan persepsi pengendara dalam terminologi kecepatan, waktu tempuh, kenyamanan, kebebasan bergerak, keamanan dan 
keselamatan. Tingkat pelayanan jalan yang bergantung kepada arus lalu lintas, berkaitan dengan kecepatan operasi yang tergantung kepada perbandingan antara arus dengan kapasitas jalan (Tamin, 2008). Tingkat pelayanan jalan dapat dibagi menjadi 6 kriteria seperti yang ada pada tabel di bawah ini.

\section{Tabel 1}

Tingkat Pelayanan Jalan

\begin{tabular}{clc}
$\begin{array}{c}\text { Tingkat } \\
\text { Pelayanan }\end{array}$ & \multicolumn{3}{c}{ Karakteristik Lalu Lintas } & $\begin{array}{c}\text { Perbandingan } \\
\text { V/C }\end{array}$ \\
\hline $\mathrm{A}$ & $\begin{array}{l}\text { Arus lancar, volume rendah, } \\
\text { dan kecepatan tinggi. }\end{array}$ & $<0,19$ \\
\hline $\mathrm{B}$ & $\begin{array}{l}\text { Arus stabil, volume sesuai } \\
\text { untuk luar kota, dan kecepatan }\end{array}$ & $0,20-0,44$ \\
& terbatas. & \\
\hline $\mathrm{C}$ & $\begin{array}{l}\text { Arus stabil, volume sesuai } \\
\text { untuk jalan kota, dan }\end{array}$ & $0,45-0,74$ \\
& $\begin{array}{l}\text { kecepatan dipengaruhi oleh } \\
\text { lalu lintas. }\end{array}$ \\
\hline D & $\begin{array}{l}\text { Arus mendekati tidak stabil, } \\
\text { kecepatan rendah. }\end{array}$ \\
\hline E & $\begin{array}{l}\text { Arus tidak stabil, volume } \\
\text { mendekati kapasitas, dan }\end{array}$ & $0,85-1,00$ \\
kecepatan rendah. & $\begin{array}{l}\text { Arus yang terlambat, volume } \\
\text { melebihi kapasitas, dan } \\
\text { kecepatan rendah. }\end{array}$ \\
\hline F
\end{tabular}

Sumber : Edward K. Morlok, Pengantar Teknik dan Perencanaan Transportasi, 1992.

Pada daerah perkotaan sering terjadi kemacetan yang merupakan permasalahan dalam lalu lintas, seperti volume lalu lintas yang melebihi lalu lintas jalan dan perilaku pengguna jalan yang tidak tertib. Apabila hasil analisis menunujukkan kinerja lalu lintas yang buruk, maka perlu evaluasi terhadap hal yang menjadi penyebab permasalahan lalu lintas dan solusi dari permasalahan tersebut.

Manajemen lalu lintas dapat diterapkan dalam melakukan pencegahan dan penanggulangan terhadap permasalahan yang terjadi dalam lalu lintas. Manajemen lalu lintas bertujuan untuk mengoptimalkan fungsi dari penggunaan jalan guna meningkatkan keselamatan, ketertiban, dan kelancaran lalu lintas (Gowa \& Setiawan, 2017). Kegiatan manajemen lalu lintas terdiri dari perencanaan, pengaturan, rekayasa, pengendalian, serta pengawasan pada lalu lintas.

Manajeman lalu lintas atau traffic management adalah suatu upaya untuk memanfaatkan semaksimal mungkin dari sistem jaringan jalan yang ada, sehingga dapat menampung lalu lintas sebanyak mungkin dan memperhatikan keterbatasan lingkungan 
(kapasitas), memberikan prioritas bagi pengguna jalan tertentu, dan menjaga kecelakaan lalu lintas seminim mungkin (Indrayana \& Agung, 2013).

Persoalan dasar lalu lintas sebenarnya sederhana, yaitu tingginya volume kendaraan yang melintasi suatu ruas jalan. Namun, kapasitas jalan yang tersedia rendah. Penanggulangan persoalan tersebut dapat dipilih dari tiga kemungkinan berikut ini (Kolinug et al., 2013) :

- Membangun jalan secukupnya dengan ukuran sesuai dengan kebutuhan.

- Batasi permintaan akan jalan dengan membatasi jumlah kendaraan yang dapat melewati ruas jalan tersebut.

- Membangun jalan tambahan, kemudian menggunakan jalan tersebut serta jaringan jalan jalan yang sudah ada sampai batas maksimum, dan pada saat yang sama melakukan pengendalian perkembangan permintaan sejauh mungkin dapat dilakukan.

Pendapat lainya dikemukakan oleh Tamin, dalam memecahkan persoalan lalu lintas pada perkotaan dapat dilakukan dengan cara sebagai berikut (UMUM, 2005) :

- Meredam atau memperkecil tingkat kebutuhan transportasi (sistem kegiatan).

- Meningkatkan kapasitas serta efisiensi dari sistem prasarana transportasi yang ada (sistem jaringan).

- Memperlancar sistem pergerakan melalui kebijakan rekayasa dan manajemen lalu lintas (sistem pergerakan).

- Peningkatan peranan sistem kelembagaan, peran swasta, masyarakat, penegak hukum, dll.

\section{Hasil dan Pembahasan}

Hasil perolehan data dari pelaksanaan survei yang dilakukan selama 2 hari adalah berupa data kondisi geometrik jalan, jumlah arus kendaraan, hambatan samping dan waktu tempuh kendaraan. Analisis yang dilakukan adalah mengenai kinerja lalu lintas pada Jalan Raya Kalibata dan evaluasi terhadap kinerja jalan tersebut.

Jalan Raya Kalibata termasuk kedalam tipe jalan 4 Lajur 2 Arah Terbagi (4/2 D). Tabel di bawah menunjukkan kondisi geometrik atau dimensi yang terdapat pada Jalan Raya Kalibata.

\section{Tabel 2}

Kondisi Geometrik Jalan Raya Kalibata

\begin{tabular}{|c|c|c|c|c|c|}
\hline Ruas & $\begin{array}{c}\text { Lebar } \\
\text { Lajur } \\
\text { m }\end{array}$ & $\begin{array}{c}\text { Lebar } \\
\text { Jalur } \\
\text { m }\end{array}$ & $\begin{array}{c}\text { Lebar } \\
\text { Median } \\
\text { m }\end{array}$ & $\begin{array}{c}\text { Lebar } \\
\text { Trotoar } \\
\text { m }\end{array}$ & $\begin{array}{c}\text { Lebar } \\
\text { Kreb } \\
\text { m }\end{array}$ \\
\hline Segmen & 3,60 & & \multirow{4}{*}{4,20} & \multirow{2}{*}{4,26} & \multirow{2}{*}{0,16} \\
\hline 1 & 3,60 & 7,20 & & & \\
\hline Segmen & 3,60 & \multirow{2}{*}{7,20} & & \multirow{2}{*}{4,20} & \multirow{2}{*}{0,16} \\
\hline 2 & 3,60 & & & & \\
\hline
\end{tabular}

Berdasarkan Tabel 2 dapat diketahui jumlah arus kendaraan maksimum untuk segmen 1 terjadi pada hari Rabu, 7 April 2021, yaitu sebanyak 5296 kend/jam. 
Sedangkan untuk segmen 2 jumlah arus kendaraan maksimum juga terjadi pada hari Rabu, 7 April 2021, sebanyak 4232 kend/jam.

Tabel 3

Jumlah Arus Kendaraan Selama 1 Jam

\begin{tabular}{|c|c|c|c|c|c|}
\hline Periode & Ruas & kend/jam & kend/jam & $\begin{array}{c}\text { MC } \\
\text { kend/jam }\end{array}$ & $\begin{array}{c}\text { Arus } \\
\text { Total } \\
\text { kend/jam }\end{array}$ \\
\hline \multicolumn{6}{|c|}{ Selasa, 6 April 2021} \\
\hline \multirow{2}{*}{$\begin{array}{c}07.00- \\
08.00\end{array}$} & 1 & 1208 & 24 & 3352 & 4584 \\
\hline & 2 & 1044 & 20 & 2672 & 3736 \\
\hline \multirow{2}{*}{$\begin{array}{c}08.00- \\
09.00\end{array}$} & 1 & 1464 & 28 & 3600 & 5092 \\
\hline & 2 & 1168 & 24 & 2924 & 4116 \\
\hline \multirow{2}{*}{$\begin{array}{c}09.00- \\
10.00\end{array}$} & 1 & 1496 & 16 & 3436 & 4948 \\
\hline & 2 & 1196 & 16 & 2740 & 3952 \\
\hline \multicolumn{6}{|c|}{ Rabu, 7 April 2021} \\
\hline \multirow{2}{*}{$\begin{array}{c}07.00- \\
08.00\end{array}$} & 1 & 1424 & 20 & 3404 & 4848 \\
\hline & 2 & 1112 & 20 & 2736 & 3868 \\
\hline \multirow{2}{*}{$\begin{array}{c}\text { 08.00 - } \\
09.00\end{array}$} & 1 & 1496 & 28 & 3772 & 5296 \\
\hline & 2 & 1248 & 28 & 2956 & 4232 \\
\hline \multirow{2}{*}{$\begin{array}{c}09.00- \\
10.00\end{array}$} & 1 & 1476 & 20 & 3580 & 5076 \\
\hline & 2 & 1052 & 24 & 2824 & 3900 \\
\hline
\end{tabular}

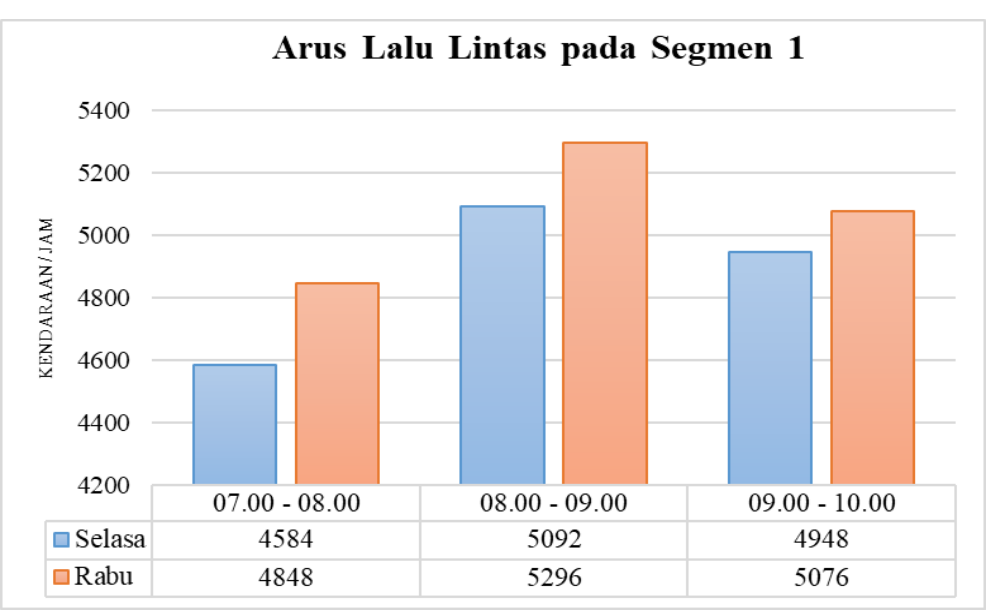

Gambar 5

Grafik Arus Lalu Lintas pada Segmen 1

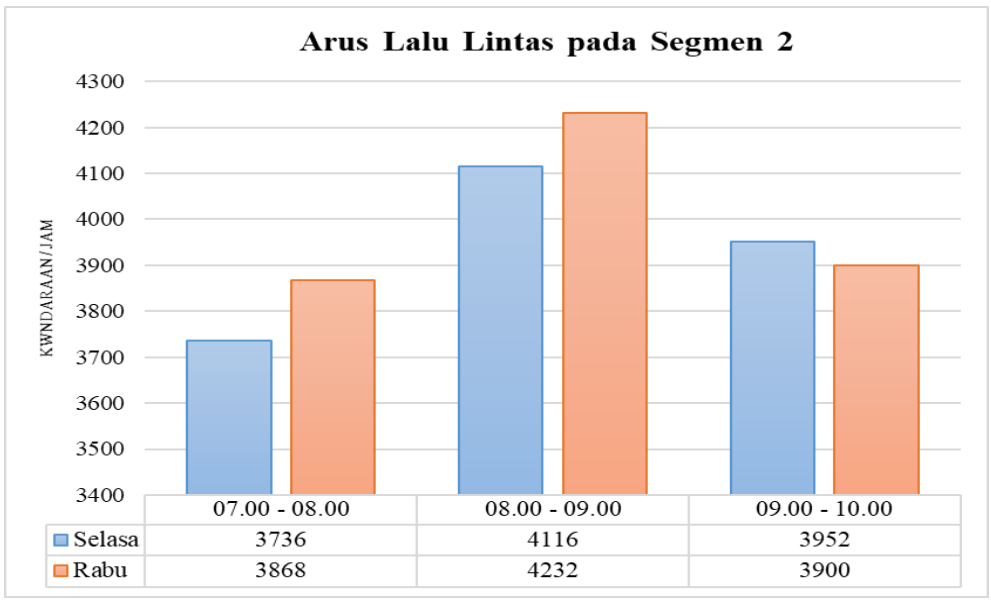




\section{Gambar 6 \\ Grafik Arus Lalu Lintas pada Segmen 2}

Pada tabel dan grafik di atas, satuan yang digunakan masih menggunakan kend/jam, sedangkan untuk melakukan analisis satuan perlu diubah ke dalam smp/jam untuk menyamakan ukuran kendaraan.

$$
\begin{aligned}
\text { Q Segmen } 1 & =\left(\mathrm{Q}_{\mathrm{LV}} \mathrm{x} \operatorname{emp}_{\mathrm{LV}}\right)+\left(\mathrm{Q}_{\mathrm{HV}} \mathrm{x} \operatorname{emp}_{\mathrm{HV}}\right)+\left(\mathrm{Q}_{\mathrm{MC}} \mathrm{x} \operatorname{emp}_{\mathrm{MC}}\right) \\
& =(1496 \times 1,00)+(28 \times 1,20)+(3772 \times 0,25) \\
& =1496+33,6+943 \\
& =2472,6 \mathrm{smp} / \mathrm{jam}
\end{aligned}
$$

$$
\begin{aligned}
\text { Q Segmen 2 } & =\left(\mathrm{Q}_{\mathrm{LV}} \mathrm{x} \operatorname{emp}_{\mathrm{LV}}\right)+\left(\mathrm{Q}_{\mathrm{HV}} \mathrm{x} \operatorname{emp}_{\mathrm{HV}}\right)+\left(\mathrm{Q}_{\mathrm{MC}} \mathrm{x} \operatorname{emp}_{\mathrm{MC}}\right) \\
& =(1248 \times 1,00)+(28 \times 1,20)+(2956 \mathrm{x} 0,25) \\
& =1248+33,6+739 \\
& =2020,6 \mathrm{smp} / \mathrm{jam}
\end{aligned}
$$

Berdasarkan hasil perhitungan menggunakan rumus, maka jumlah arus lalu lintas yang akan digunakan dalam analisis pada segmen 1 adalah sebanyak 2472,6 smp/jam dan pada segmen 2 adalah 2020,6 smp/jam.

Tabel 4

\begin{tabular}{cccrcc}
\multicolumn{7}{c}{ Jumlah Hambatan Samping Selama 1 Jam } \\
$\begin{array}{c}\text { Periode } \\
\text { Waktu }\end{array}$ & $\begin{array}{c}\text { Ruas } \\
\text { Jalan }\end{array}$ & PED & PCV & EEV & SMV \\
\hline Selasa, 6 & April 2021 & & & & \\
\hline $\mathbf{0 7 . 0 0}-$ & Segmen 1 & 100 & 44 & 72 & 44 \\
$\mathbf{0 8 . 0 0}$ & Segmen 2 & 152 & 104 & 108 & 112 \\
\hline $\mathbf{0 8 . 0 0}-$ & Segmen 1 & 116 & 60 & 96 & 68 \\
$\mathbf{0 9 . 0 0}$ & Segmen 2 & 176 & 80 & 184 & 128 \\
\hline $\mathbf{0 9 . 0 0}-$ & Segmen 1 & 96 & 36 & 104 & 64 \\
$\mathbf{1 0 . 0 0}$ & Segmen 2 & 168 & 72 & 164 & 108 \\
\hline Rabu, 7 April 2021 & & & & \\
\hline $\mathbf{0 7 . 0 0}-$ & Segmen 1 & 96 & 64 & 92 & 60 \\
$\mathbf{0 8 . 0 0}$ & Segmen 2 & 164 & 80 & 132 & 108 \\
\hline $\mathbf{0 8 . 0 0}-$ & Segmen 1 & 120 & 72 & 100 & 68 \\
\hline $\mathbf{0 9 . 0 0}$ & Segmen 2 & 184 & 112 & 148 & 156 \\
\hline $\mathbf{0 9 . 0 0}-$ & Segmen 1 & 84 & 64 & 116 & 56 \\
\hline $\mathbf{1 0 . 0 0}$ & Segmen 2 & 156 & 88 & 168 & 132 \\
\hline
\end{tabular}

Analisis terhadap hambatan samping digunakan hasil data dari pengamatan pada hari Rabu, 7 April 2021 untuk jam 08.00 - 09.00 WIB, disamakan seperti data arus lalu lintas puncak. Berdasarkan hasil pengamatan yang ada pada tabel 4, frekuensi kejadian perlu dikalikan dengan bobot yang ada baik pada segmen 1 maupun segmen 2 .

Tabel 5

Jumlah Hambatan Samping Pada Segmen 1 


\begin{tabular}{clccc}
\hline No. & $\begin{array}{l}\text { Hambatan } \\
\text { Samping }\end{array}$ & Bobot & $\begin{array}{l}\text { Frekuensi } \\
\text { Kejadian }\end{array}$ & $\begin{array}{c}\text { Frekuensi } \\
\text { Bobot }\end{array}$ \\
\hline $\mathbf{1}$ & PED & 0,5 & 120 & 60,0 \\
\hline $\mathbf{2}$ & PCV & 1,0 & 72 & 72,0 \\
\hline $\mathbf{3}$ & EEV & 0,7 & 100 & 70,0 \\
\hline $\mathbf{4}$ & SMV & 0,4 & 68 & 27,2 \\
\hline & & & TOTAL & 229,2 \\
\hline
\end{tabular}

Tabel 6

Jumlah Hambatan Samping Pada Segmen 2

\begin{tabular}{clccc} 
No. & $\begin{array}{l}\text { Hambatan } \\
\text { Samping }\end{array}$ & Bobot & $\begin{array}{c}\text { Frekuensi } \\
\text { Kejadian }\end{array}$ & $\begin{array}{c}\text { Frekuensi } \\
\text { Bobot }\end{array}$ \\
\hline $\mathbf{1}$ & PED & 0,5 & 184 & 92,0 \\
\hline $\mathbf{2}$ & PCV & 1,0 & 112 & 112,0 \\
\hline $\mathbf{3}$ & EEV & 0,7 & 148 & 103,6 \\
\hline $\mathbf{4}$ & SMV & 0,4 & 156 & 62,4 \\
& & & TOTAL & 370,0 \\
\hline
\end{tabular}

Tabel 7

Kelas Hambatan Samping

\begin{tabular}{lccl}
\hline $\begin{array}{l}\text { Kelas } \\
\text { Hambatan } \\
\text { Samping }\end{array}$ & Kode & $\begin{array}{c}\text { Jumlah Berbobot } \\
\text { Kejadian per 200 m } \\
\text { per jam (dua sisi) }\end{array}$ & \multicolumn{1}{c}{ Kondisi Khusus } \\
\hline $\begin{array}{l}\text { Sangat } \\
\text { Rendah }\end{array}$ & VL & $<100$ & $\begin{array}{l}\text { Daerah permukiman, jalan } \\
\text { dengan jalan samping. }\end{array}$ \\
\hline Rendah & L & $100-299$ & $\begin{array}{l}\text { Daerah Permukiman, beberapa } \\
\text { kendaraan umum, dsb. }\end{array}$ \\
\hline Sedang & M & $300-499$ & $\begin{array}{l}\text { Daerah Industri, beberapa took di } \\
\text { sisi jalan. }\end{array}$ \\
\hline Tinggi & H & $500-899$ & $\begin{array}{l}\text { Daerah komersial, aktivitas sisi } \\
\text { jalan tinggi. }\end{array}$ \\
\hline Sangat Tinggi & VH & $>900$ & $\begin{array}{l}\text { Daerah komersial dengan } \\
\text { aktivitas pasar di samping jalan. }\end{array}$ \\
\hline
\end{tabular}

Sumber : Direktorat Jendral Bina Marga, Manual Kapasitas Jalan Indonesia, 1997.

Berdasarkan hasil perhitungan pada tabel 5, total frekuensi kejadian pada segmen 1 adalah 229,2 kejadian dan termasuk ke dalam kelas hambatan samping rendah (L). Sedangkan untuk segmen 2 total frekuensi kejadiannya adalah 370,0, maka termasuk kedalam kelas hambatan samping sedang (M).

Kecepatan arus bebas (FV) dianalisis berdasarkan MKJI 1997 dengan hasil perhitungan menggunakan rumus (1). Hasil perhitungan didapatkan nilai FV untuk segmen 1 adalah 55,29 km/jam, sedangkan untuk segmen 2 adalah 53,01 km/jam.

Tabel 7

Hasil Perhitungan Kecepatan Arus Bebas

\begin{tabular}{cccccc}
\hline $\begin{array}{c}\text { Ruas } \\
\text { Jalan }\end{array}$ & $\begin{array}{c}\text { FVo } \\
\mathbf{k m} / \mathbf{j a m}\end{array}$ & $\begin{array}{c}\mathbf{F V w} \\
\mathbf{k m} / \mathbf{j a m}\end{array}$ & FFVsf & FFVes & $\begin{array}{c}\mathbf{F V} \\
\mathbf{k m} / \mathbf{j a m}\end{array}$ \\
\hline $\mathbf{1}$ & 55 & 2 & 0,97 & 1 & 55,29 \\
\hline $\mathbf{2}$ & 55 & 2 & 0,93 & 1 & 53,01 \\
\hline
\end{tabular}


Kapasitas (C) dianalisis berdasarkan MKJI 1997 dengan hasil perhitungan menggunakan rumus (2). Hasil perhitungan didapatkan nilai $\mathrm{C}$ untuk segmen 1 adalah 3226,08 smp/jam, sedangkan untuk segmen 2 adalah 3123,12 smp/jam.

Tabel 8

Hasil Perhitungan Kapasitas

\begin{tabular}{ccccccc}
\hline $\begin{array}{c}\text { Ruas } \\
\text { Jalan }\end{array}$ & Co & FCw & FCsp & FCsf & FCes & $\begin{array}{c}\text { C } \\
\text { smp/jam }\end{array}$ \\
\hline 1 & 3300 & 1,04 & 1 & 0,94 & 1 & 3226,08 \\
\hline 2 & 3300 & 1,04 & 1 & 0,91 & 1 & 3123,12 \\
\hline
\end{tabular}

Nilai dari derajat kejenuhan (DS) dapat dihitung menggunakan rumus (3). Dari hasil perhitungan yang telah dilakukan nilai DS untuk segmen 1 adalah 0,766 melebihi 0,75 yang dibatasi oleh MKJI 1997. Berdasarkan nilai DS tingkat pelayanan jalan pada segmen 1 termasuk kedalam tingkat D yang memiliki karakteristik lalu lintas dengan arus mendekati stabil dan kecepatan kendaraan rendah. Sedangkan hasil perhitungan DS untuk segmen 2 didapat hasil 0,647, maka termasuk ke dalam tingkat pelayanan jalan C, yang memiliki karakteristik lalu lintas dengan arus stabil, volume sesuai untuk jalan kota dan kecepatan dipengaruhi oleh lalu lintas.

Tabel 9

Hasil Perhitungan Derajat

\begin{tabular}{cccc}
\multicolumn{4}{c}{ Kejenuhan } \\
$\begin{array}{c}\text { Ruas } \\
\text { Jalan }\end{array}$ & $\begin{array}{c}\mathbf{Q} \\
\text { smp/jam }\end{array}$ & $\begin{array}{c}\mathbf{C} \\
\text { smp/jam }\end{array}$ & DS \\
\hline 1 & 2472,6 & 3226,08 & 0,766 \\
\hline 2 & 2020,6 & 3123,12 & 0,647 \\
\hline
\end{tabular}

Waktu tempuh dari sampel setiap jenis kendaraan baik LV, HV, maupun MC diambil untuk menganalisis kecepatan rata-rata. Selanjutnya, waktu tempuh tersebut akan dibagi dengan jarak tempuhnya sesuai dengan rumus (4). Data yang digunakan untuk menganalisis kecepatan rata-rata kendaraan, menggunakan data sampel kendaraan pada hari Rabu, 7 April 2021 untuk jam 08.00-09.00. Yang mana, selama masa pengamatan pada hari dan jam tersebut terjadi volume lalu lintas yang paling tinggi.

Analisis kecepatan rata-rata kendaraan untuk segmen 1 berdasarkan rumus (4) didapatkan hasil sebesar $21,830 \mathrm{~km} / \mathrm{jam}$. Sedangkan untuk segmen 2 adalah 32,427 $\mathrm{km} / \mathrm{jam}$.

Tabel 10

Hasil Perhitungan Kecepatan Rata - Rata Pada Segmen 1

\begin{tabular}{cccccccc}
\hline \multirow{2}{*}{ Kend } & \multirow{2}{*}{$\begin{array}{c}\text { Jarak } \\
\text { km }\end{array}$} & \multicolumn{3}{c}{$\begin{array}{c}\text { Waktu Tempuh } \\
\text { (s) }\end{array}$} & \multicolumn{3}{c}{ Kecepatan (km/jam) } \\
\cline { 3 - 8 } & & LV & HV & MC & LV & HV & MC \\
\hline 1 & 0,2 & 35 & 37 & 31 & 20,571 & 19,459 & 23,226 \\
\hline
\end{tabular}




\begin{tabular}{|c|c|c|c|c|c|c|c|}
\hline 2 & 0,2 & 31 & 42 & 29 & 23,226 & 17,143 & 24,828 \\
\hline 3 & 0,2 & 33 & 39 & 24 & 21,818 & 18,462 & 30,000 \\
\hline 4 & 0,2 & 34 & 38 & 27 & 21,176 & 18,947 & 26,667 \\
\hline 5 & 0,2 & 37 & 39 & 30 & 19,459 & 18,462 & 24,000 \\
\hline & \multicolumn{4}{|c|}{ Kecepatan $(\mathrm{km} / \mathrm{jam})$} & 21,250 & 18,495 & 25,744 \\
\hline
\end{tabular}

Tabel 11

Hasil Perhitungan Kecepatan Rata - Rata Pada Segmen 2

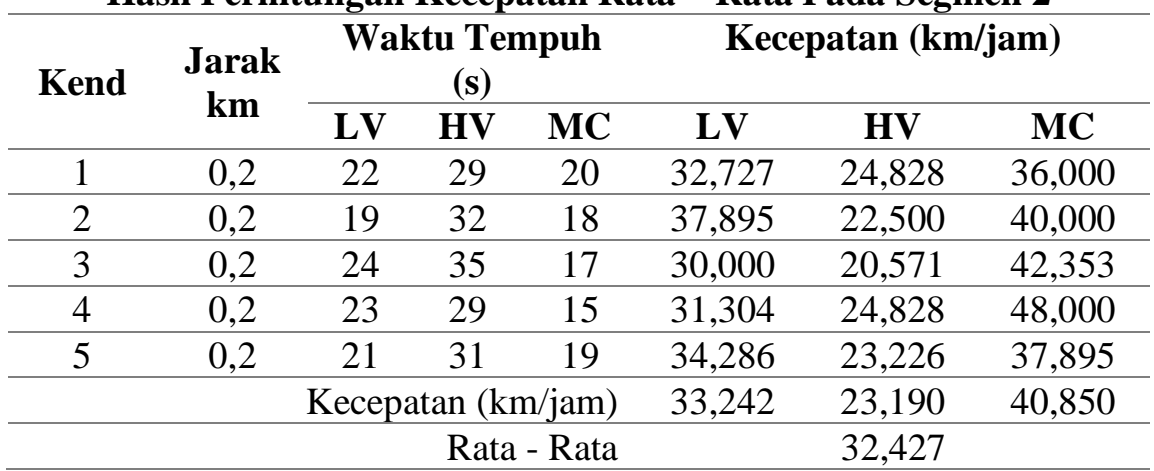

Hasil nilai dari derajat kejenuhan untuk segmen 1 adalah 0,766 dan termasuk kedalam tingkat pelayanan jalan D. Oleh karena itu, perlu dilakukan evaluasi trhadap kinerja pada segmen 1 agar dapat menurunkan nilai dari derajat kejenuhan.

Sedangkan hasil nilai derajat kejenuhan pada segmen 2 menunjukkan angka 0,647 dan termasuk kedalam tingkat pelayanan jalan C. Walaupun masih jauh dari batas 0,75 evaluasi terhadap kinerja tetap perlu dilakukan. Hal ini karena terjadinya penambahan penduduk maupun kepemilikan kendaraan pribadi setiap tahunnya, terutama pada daerah perkotaan.

Karena nilai derajat kejenuhan pada segmen 1 melebihi nilai yang dibatasi, maka perlu dilakukan evaluasi baik untuk factor penyebab yang menjadi permasalahan lalu lintas, maupun solusi untuk memperbaiki kinerja lalu lintas pada Jalan Raya Kalibata tersebut.

Berdasarkan analisis dari pengamatan yang telah dilakukan, penyebab persoalan lalu lintas atau kemacetan yang terjadi pada Jalan Raya Kalibata diantaranya adalah :

1. Pengurangan Lajur

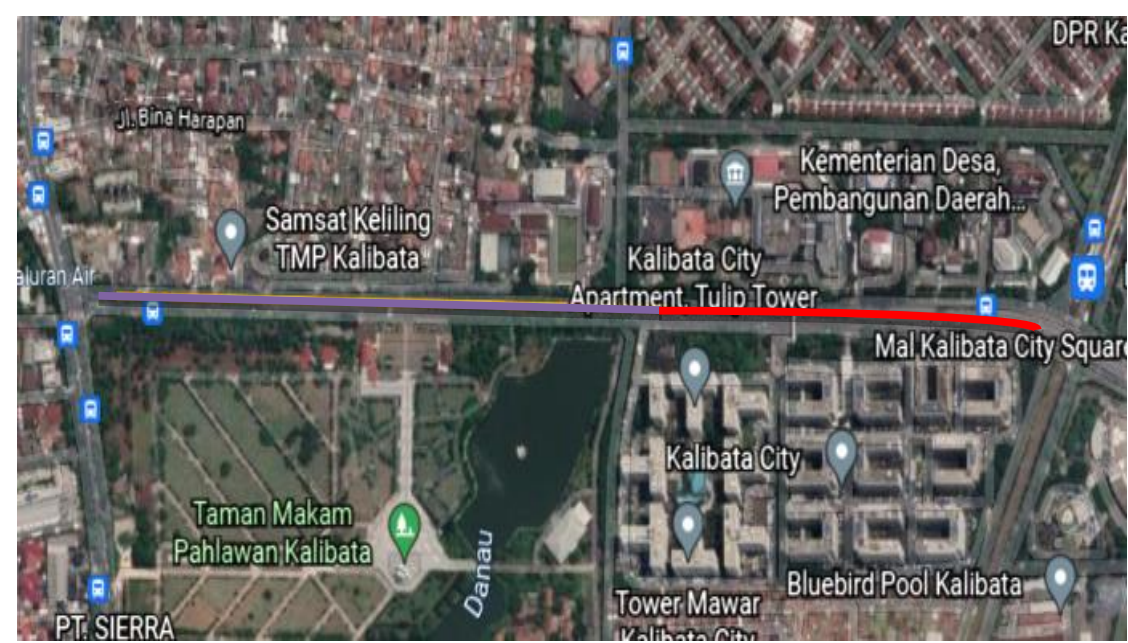

Jurnal Syntax Admiration, Vol. 2 No. 9 September 2021 


\section{Gambar 4}

\section{Lokasi Pengurangan Lajur pada Jalan Raya Kalibata}

Pengurangan lajur pada Jalan Raya Kalibata terjadi di depan Apartemen Kalibata City. Seperti terlihat pada gambar 4, untuk garis berwarna merah menunjukkan untuk jalan dengan 3 lajur. Sedangkan garis bewarna kuning menunjukkan untuk jalan dengan 2 lajur.

2. Simpang Bersinyal

Pada simpang Jalan Raya Kalibata dan Jalan Raya Pasar Minggu terdapat simpang 3 lengan bersinyal. Simpang ini menjadi salah satu penyebab utama masalah kemacetan yang terjadi pada segmen 1, karena terjadi tundaan kendaraan. Berdasarkan hasil pengamatan untuk waktu tunggu lampu merah pada segmen 1 adalah 135 detik. Sedangkan lampu hijau menyala selama 54 detik.

\section{Perilaku Pengemudi}

Saat melakukan pengamatan untuk mengetahui penyebab kemacetan, terlihat seperti pada ilustrasi seperti terlihat pada gambar 5, yang seharusnya jalan memiliki 2 lajur, karena pengemudi yang tidak sabar untuk menunggu antrian, maka pengemudi membuat jalan mejadi 3 lajur. Hal ini menghalangi jalan pengemudi yang ingin langsung belok ke kiri. Sehingga makin memperburuk keadaan dan memperpanjang tumpukan kendaraan.

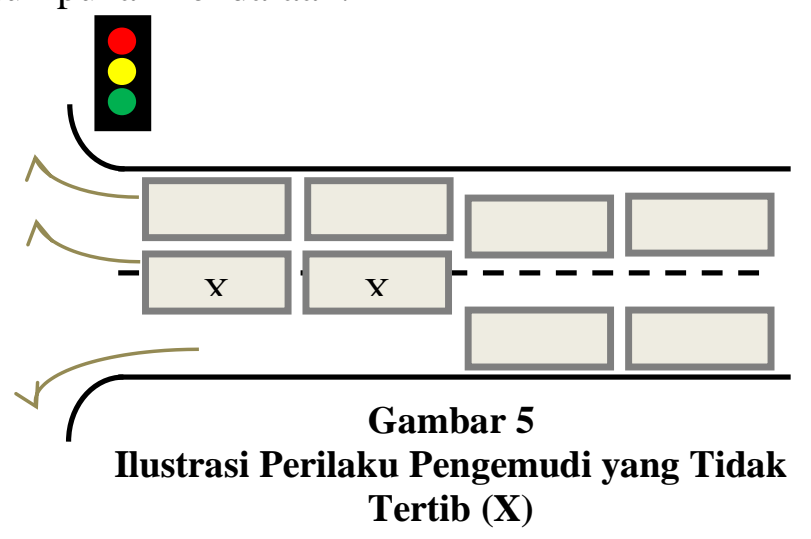

\section{Tingginya Angka Penggunaan Mobil Pribadi}

Tingginya angka penggunaan mobil pribadi bukan hanya menjadi permasalahan yang ada di Jalan Raya Kalibata saja, namun hampir seluruh kota mengalaminya. Berdasarkan data BPS Provinsi DKI Jakarta jumlah mobil penumpang untuk tahun 2019 mengalami kenaikan sebesar 0,60\% dari tahun sebelumnya, dengan jumlah kendaraan sebanyak 2.805.989 Unit. Sedangkan penggunaan sepeda motor mengalami kenaikan sebesar $0,72 \%$, dengan jumlah kendaraan sebanyak 8.1945.90 unit (Statistik, 2019). 
Banyak masyarakat yang masih enggan menaiki kendaraan umum beberapa penyebabnya adalah jumlah armada yang tidak memadai sehingga harus berdesakan antara penumpang, waktu tunggu yang lama dan kendaraan umum sering tidak tepat waktu. Sehingga membuat masyarakat lebih berminat menaiki kendaraan pribadi.

Beberapa penyebab utama persoalan kemacetan pada Jalan Raya Kalibata, dapat diambil beberapa solusi untuk mengatasi persoalan tersebut. Pada simpang bersinyal yang terdapat pada ujung segmen 1, waktu tunggu atau antrian 135 detik tidak dapat diubah menjadi lebih cepat. Penyebabnya karena kemacetan yang terjadi pada Jalan Raya Pasar Minggu lebih panjang dibandingkan dengan Jalan Raya Kalibata. Ketika melakukan pengamatan, panjang kemacetan yang terjadi pada Jalan Raya Pasar Minggu adalah sekitar 1,4 - 1,5 km, sedangkan pada Jalan Raya Kalibata adalah sekitar 700 m. Dikhawatirkan jika waktu tunggu pada Jalan Raya Kalibata dikurangi maka akan berdampak pada Jalan Raya Pasar Minggu dan menyebabkan kemacetan pada jalan tersebut menjadi lebih parah.

Tingginya angka penggunaan mobil pribadi, bukan hanya menjadi masalah pada Jalan Raya Kalibata saja, namun menjadi masalah Indonesia. Diharapkan pemerintah dapat memperbaiki fasilitas kendaraan umum lebih baik lagi dan menekan angka kepemilikan mobil pribadi. Seperti di Singapura untuk menekan angka kepemilkan mobil pribadi, pada ruas jalan dibuat sistem ERP (Electronic Road Pricing) dan jika ingin membeli mobil harus memiliki suatu sertifikat atau lisensi yang tidak murah harganya. Namun, hal ini tidak mudah dilakukan di Indonesia, selain karena fasilitas yang belum memadai, juga karena pola pikir masyarakatnya sendiri.

Solusi yang dapat diterapkan dalam megatasi persoalan kemacetan pada Jalan Raya Kalibata adalah sebagai berikut :

1. Kesadaran dari diri setiap pengguna jalan

Kesadaran masing - masing pengemudi dan menerapkan disiplin berkendara untuk tidak saling meyalip serta harus menaati peraturan dan rambu yang tersedia. Kemudian untuk penyebrang jalan diharapkan untuk menyberang pada tempatnya baik pada zebra cross maupun JPO.

2. Tidak berpindah - pindah lajur ketika berkendara

Hal ini harus dilakukan karena pengemudi tidak dapat memprediksi apa yang pengemudi lain akan lakukan. Kemudian, hal ini membuat pengemudi lain harus mengerem kendaraannya agar tidak terjadi kecelakaan, sehingga membuat laju kendaraan melambat atau bahkan harus berhenti. Akibatnya adalah akan membuat antrian kendaraan ketika arus lalu lintas sedang tinggi.

3. Perlu adanya tindakan dari aparat yang berwenang.

Aparat yang berwenang perlu menertibkan keberadaan Pak Ogah di jalan. Karena, selain dapat memperburuk kemacetan yang ada, dengan keberaaanya dapat menimbulkan bahaya bagi dirinya maupun pengguna jalan lainnya. Selain itu, para pengguna jalan yang tidak mematuhi rambu-rambu lalu lintas juga harus ditertibkan. 
4. Mengurangi jumlah atau jarak perjalanan

Dapat dilakukan dengan dengan membuat aktivitas lebih dekat dari lokasi tempat tinggal, atau mengganti aktivitas dengan menggunakan teknologi komunikasi. Dengan hal ini diharapkan kemacetan yang terjadi akan berkurang.

5. Upaya pemerintah dalam memperbaiki pelayanan angkutan umum yang buruk

Penyebab banyak masyarakat yang lebih memilih untuk menaiki kendaraan pribadi adalah karena pelayanan angkutan umum yang buruk. Contohnya adalah seringkali terjadinya keterlambatan angkutan umum yang menyebabkan penumpukan penumpang, sehingga menyebabkan penumpang harus berdesak desakkan di dalam angkutan tersebut. Hal ini yang menjadi penyebab masyarakat merasa malas untuk menaiki angkutan umum.

Namun, apabila dilihat lebih lanjut, alasan untuk keterlambatan untuk moda transportasi seperti bus way salah satunya adalah tertahan oleh kemacetan. Oleh karena itu, perlu adanya kesadaran dari setiap masyarakat untuk meninggalkan penggunaan kendaraan pribadi dan lebih memilih menggunaan moda transportasi umum. Sehingga, jumlah kendaraan atau arus lalu lintas pada jalan dapat menurun.

6. Upaya pemerintah dalam memperbaiki sistem transportasi

Pemerintah Provinsi DKI Jakarta telah meluncurkan program yang bernama Pola Transportasi Makro (PTM) yang merupakan sebuah sistem yang diciptakan secara komprehensif untuk menciptakan penataan sistem transportasi yang terintegrasi di Jakarta. Tujuan membuat sebuah sistem lalu lintas dan transportasi yang bisa memberikan kenyamanan kepada masyarakat dengan tingkat efektivitas dan efisiensi yang tinggi.

Program PTM terdiri 3 strategi atau kebijakan, yaitu pengembangan angkutan umum massal, pembangunan infrastruktur, dan peraturan - peraturan. Dimana hal tersebut dilakukan untuk mengendalikan jumlah kendaraan pribadi, karena jika tidak dilakukan pengendalian akan terjadi kemacetan total di Jakarta. Pemerintah sangat memprioritaskan pengembangan angkutan umum massal sebagai tulang punggung transportasi di Jakarta.

Strategi pembangunan angkutan umum massal terdiri dari BRT (Busway), MRT (Mass Rapid Transit), LRT (Light Rail Transit), dan water ways. Diantara 4 jenis angkutan umum tersebut, hanya water ways yang belum dilakukan. Diharapkan dengan adanya angkutan umum tersebut, masyarakat akan memanfaatkan dan menggunakannya. Karena, keberhasilan pengembangan angkutan massal perlu dukungan dari semua pihak. Keberhasilan sistem transportasi juga bergantung kepada integrasi antara moda transportasi, baik secara fisik dan tiket. Kemudian, harus ditunjang dengan fasilitas park and ride, serta kemudahan transfer antar moda transportasi.

7. Membiasakan diri dengan menggunakan atau memanfaatkan angkutan umum

Menggunakan angkutan umum seperti bus atau kereta akan mengurangi penggunaan angkutan pribadi, sehingga perpindahan emisi oleh angkutan pribadi 
tergantikan oleh angkutan umum yang lebih ramah lingkungan. target untuk mencapai kota yang layak dengan transportasi berkelanjutan perlu dipahami dan diupayakan oleh semua masyarakat.

\section{Kesimpulan}

Pengamatan dilakukan selama 2 hari, yaitu pada hari Selasa, 6 April 2021 sampai Rabu, 7 April 2021 untuk pukul 07.00 - 10.00 WIB. Arus puncak selama waktu pengamatan untuk segmen 1 maupun segmen 2, terjadi pada hari Rabu, 7 April 2021 untuk periode waktu 08.00 - 09.00 WIB. Hasil analisis nilai derajat kejenuhan untuk segmen 1 adalah 0,766, sedangkan untuk segmen 2 adalah 0,647. Hal yang dapat dilakukan untuk mengatasi permasalahan lalu lintas yang ada pada Jalan Raya Kalibata adalah kesadaran dari diri setiap pengguna jalan, tidak berpindah - pindah lajur ketika berkendara, perlu adanya tindakan dari aparat yang berwenang, mengurangi jumlah atau jarak perjalanan, upaya pemerintah dalam memperbaiki pelayanan angkutan umum yang buruk, upaya pemerintah dalam memperbaiki sistem transportasi, serta membiasakan diri dengan menggunakan atau memanfaatkan angkutan umum. 


\section{BIBLIOGRAFI}

Desembardi, F., Sukrisman, A., Pristianto, H., \& Ulayanto, H. (2018). Analisis Kinerja Ruas Jalan Terhadap Pengaruh Hambatan Samping Pada Jalan Am Sangaji Gonof Km. 12 Kota Sorong. Google Scholar

Gowa, C. B., \& Setiawan, A. (2017). Analisis Kinerja Lalu Lintas Di Jalan Sekitar Terminal. Google Scholar

Gridoto.Com. (2018). Mengenal Hambatan Samping, Salah Satu Penyebab Kemacetan [Online]. Gridoto.Com. Https://Www.Gridoto.Com/Amp/Read/221038776/Menge nal-Hambatan-Samping-Salah-Satu-Penyebab-Kemacetan. Google Scholar

Ilmusipil.Com. (2009). Manajemen Lalu Lintas [Online]. Ilmusipil.Com. Https://Www.Ilmusipil.Com/Manajemen-Lalu-Lintas. Google Scholar

Indonesia, M. K. J. (1997). Departemen Pekerjaan Umum. Direktorat Jenderal Bina Marga. Google Scholar

Indrayana, I., \& Agung, G. N. G. (2013). Analisis Kinerja Ruas Jalan Dan Biaya Perjalanan Akibat Tundaan Pada Ruas Jalan. J. Ilm. Elektron. Infra Strktur Tek. Sipil, 2. Google Scholar

Jakarta, P. D. (2007). Peraturan Gubernur Provinsi Dki Jakarta No 103 Tahun 2007 Tentang Pola Transportasi Makro. Jakarta : Sekertariat Negara. Google Scholar

Kolinug, L. A., Sendow, T. K., Jansen, F., \& Manoppo, M. R. E. (2013). Analisa Kinerja Jaringan Jalan Dalam Kampus Universitas Sam Ratulangi. Jurnal Sipil Statik, 1 (2). Google Scholar

Leksmono, S. P. (2019). Rekayasa Lalu-Linta. Edisi 3. Tim Indeks : Jakarta Barat. Google Scholar

Negara, S. (2009). Undang-Undang Republik Indonesia Nomor 22 Tahun 2009 Tentang Lalu Lintas Dan Angkutan Jalan. Jakarta Selatan: Ditlantas Babinkam Polri. Google Scholar

Perhubungan, M., Pm, N., \& Berbendera, B. K. (2015). Peraturan Menteri Perhubungan. Bandung. Pemerintah Kota Bandung. Google Scholar

Risdiyanto. (2014). Rekayasa \& Manajemen Lalu Lintas Teori Dan Aplikasi. Leutikaprio : Yogyakarta. Google Scholar

Septiansyah, M. V. M., \& Wulansari, D. N. (2018). Analisa Kinerja Ruas Jalan Medan Merdeka Barat, Dki Jakarta. Jurnal Kajian Teknik Sipil, 3 (2), 110-115. Google Scholar

Statistik, B. P. (2019). Data Dan Informasi Kemiskinan Kabupaten/Kota Tahun 2018. Jakarta: Badan Pusat Statistik. Google Scholar 
Tamin, O. Z. (2008). Perencanaan, Pemodelan Dan Rekayasa Transportasi. Bandung: ITB, 277. Google Scholar

Umum, D. P. (2005). Rde-08: Rekayasa Lalu Lintas. Google Scholar

\section{Copyright holder:}

Zahara Dwicahyanti, A.R. Indra Tjahjani (2021)

First publication right:

Jurnal Syntax Admiration

This article is licensed under:

(c) (i) (? 